\title{
Sensitivity of Five Container-grown Nursery Species to Chlorine in Overhead Irrigation Water
}

\author{
Diane Feliciano Cayanan, Youbin Zheng ${ }^{1}$, Ping Zhang, Tom Graham, \\ and Mike Dixon \\ Controlled Environment Systems Research Facility, Department of \\ Environmental Biology, University of Guelph, 50 Stone Road West, \\ Guelph, Ontario, N1G 2W1, Canada

\section{Calvin Chong} \\ Department of Plant Agriculture, University of Guelph, Guelph, Ontario, \\ N1G 2W1, Canada
}

\author{
Jennifer Llewellyn \\ Ontario Ministry of Agriculture, Food and Rural Affairs, Bovey Building, \\ University of Guelph, Guelph, Ontario, N1G 2W1, Canada
}

Additional index words. chlorine, phytotoxicity, Spiraea japonica, Hydrangea paniculata, Weigela florida, Physocarpus opulifolius, Salix integra

\begin{abstract}
Phytotoxic responses of five container-grown nursery species (Spiraea japonica 'Goldmound', Hydrangea paniculata 'Grandiflora', Weigela florida 'Alexandra', Physocarpus opulifolius 'Summer Wine', and Salix integra 'Hakura Nishiki') to chlorinated irrigation water and critical free chlorine thresholds were evaluated. Plants were overhead-irrigated with water containing $0,2.5,5,10$, and $20 \mathrm{mg} \cdot \mathrm{L}^{-1}$ of free chlorine for 6 weeks. The following measurements were used to assess the treatments: visual injury, growth, leaf chlorophyll content index, leaf chlorophyll fluorescence, leaf net $\mathrm{CO}_{2}$ exchange rate, and stomatal conductance. All species exhibited one or more signs of chlorine injury, including foliar necrotic mottling, foliar necrosis and chlorosis, decreased plant height, and increased premature abscission of foliage with species varying in sensitivity to free chlorine concentrations of irrigation water. The results indicated that the critical free chlorine threshold of $S$. japonica, $\mathrm{H}$. paniculata, $\mathrm{W}$. florida, and $S$. integra was $2.5 \mathrm{mg} \cdot \mathrm{L}^{-1}$ and $5 \mathrm{mg} \cdot \mathrm{L}^{-1}$ for $P$. opulifolius. Our results suggested that irrigation water containing free chlorine less than $2.5 \mathrm{mg} \cdot \mathrm{L}^{-1}$ should not adversely affect the growth or appearance of ornamental woody shrubs.
\end{abstract}

Water-use permits, competition for water resources, and economics have stimulated the adoption of recycling irrigation water in the greenhouse and nursery industries (Ehret et al., 2001; Hong et al., 2003; Newman, 2004; Skimina, 1992). However, the use of nondisinfected, recycled irrigation water increases the risk of spreading plant pathogens, which can result in serious disease epidemics and crop losses (Hong et al., 2003). Currently, there are effective fungicides that help manage a variety of plant pathogens such as Phytophthora spp., Pythium spp., Fusarium spp., and Rhizoctonia solani (Fueda and Hirasawa, 1994;

Received for publication 30 Aug. 2007. Accepted for publication 2 Jan. 2008.

This project was funded by Canada-Ontario Research and Development Program through Flowers Canada (Ontario) and Landscape Ontario. We thank Tom Intven from Canadale Nurseries Ltd. for providing the plants used in this research and Matt Hannaburg and Jamie Lawson for their technical support.

${ }^{1}$ To whom reprint requests should be addressed; e-mail yzheng@uoguelph.ca.
Newman, 2004), but repeated application of fungicides is increasing the development of resistance (Hong et al., 2003; Kuhajek et al., 2003) and causing environmental concerns (Schoene et al., 2006).

Other current disinfection methods of irrigation water include filtration, ultraviolet irradiation, ozonation, the use of nonionic surfactants and ionized copper, and chlorination (Ehret et al., 2001; Havard, 2003; Hong et al., 2003; Igura et al., 2004; Newman, 2004; White, 1992). Chlorination is one of the most economical water decontamination methods. It was developed to treat municipal water and still remains as one of the primary methods to disinfect water (Frink and Bugbee, 1987; Tietjen et al., 2003; White, 1992). As a result of the concern of spreading diseases throughout crops through recycled irrigation water, chlorination technology has been adopted by some nursery and greenhouse growers to disinfect their irrigation water and systems.

Literature on chlorine disinfection of fungi is limited; however, research on bacteria suggest that chlorine disinfects by disrupting various microbial subcellular components and metabolic processes, including in vitro formation of chlorinated derivatives of purine and pyrimidine nucleotide bases; oxidative decarboxylation of amino acids and other naturally occurring carboxylic acids; inhibition of enzymes involved in intermediary metabolisms; inhibition of protein biosynthesis; introduction of single- and doublestranded lesions into bacterial mutations' inhibition of membrane-mediated active transport processes and respiratory activity, uncoupling of oxidative phosphorylation accompanied by leakage of macromolecules from the cell; and physiological injury of coliform microorganisms such as Escherichia coli (Ridgway and Olson, 1982).

Chlorine demand must be considered in chlorination protocols when determining the amount of chlorine that is applied to disinfect water. Chlorine demand is the quantity of chlorine that will be consumed by organic matter and other oxidizable substances in water before a residual chlorine concentration can be obtained (Hong et al., 2003). Chlorine residual may include free residual chlorine, combined residual chlorine, or total residual chlorine. Free residual chlorine is defined as chlorine compounds in the form of dissolved chlorine gas $\left(\mathrm{Cl}_{2}\right)$, hypochlorous acid $(\mathrm{HOCl})$, or hypochlorite ion. Combined residual chlorine is defined as chlorine compounds that have reacted with ammonia or organic nitrogen in water to form chloramines or other chloro-derivatives. Compounds of combined chlorine include monochloramine, dichloramine (White, 1992), and nitrogen trichloride, which are less biocidal than free chlorine but still provide a disinfecting action (Hong et al., 2003). Total residual chlorine is defined as the sum of free and combined residual chlorine in water. Henceforth, free residual chlorine is referred to as free chlorine.

Use of chlorine in excess can cause visual injury, including chlorosis (bleaching action of tissues), necrotic mottling (red and black dark spots on the leaf surface), foliar necrosis (death of cells and cell tissue) (Schreuder and Brewer, 2001a; Vijayan and Bedi, 1989), premature abscission of foliage (Frink and Bugbee, 1987), decrease in plant growth (Brown, 1991; Carrillo et al., 1996; Karaivazoglou et al., 2005; Schreuder and Brewer, 2001b), leaf discoloration, curling of leaves (Brown, 1991; Karaivazoglou et al., 2005), cuticular damage resulting in increased rates of cuticular transpiration and decreased photosynthesis (Schreuder and Brewer, 2001b), damage to chloroplast membranes in conifers and reduced photosynthetic leaf area (Schreuder and Brewer, 2001a; Vijayan and Bedi, 1989), and marginal burning of leaves (Vijayan and Bedi, 1989).

There is limited research regarding the phytotoxic effects of chlorinated water on herbaceous ornamental and vegetable plants and even less so on woody ornamentals. Frink and Bugbee (1987) reported that geranium and begonia receiving chlorinated water declined in growth. Brown (1991) also reported reduction in height and flower and 
bud production of marigold and impatiens irrigated with chlorinated water. No research was found that has investigated the effects of chlorinated irrigation water on nursery crops irrigated daily like in typical commercial nursery operations.

The objective of this study was to investigate the phytotoxic responses and critical free chlorine threshold of five containergrown nursery liners to chlorinated irrigation water applied daily.

\section{Materials and Methods}

Plant material and treatments. Five container-grown nursery plant species were tested for their response to irrigation water containing free chlorine at concentrations of $0,2.5,5,10$, and $20 \mathrm{mg} \cdot \mathrm{L}^{-1}$. One-year-old liners of five species [spirea (Spiraea japonica 'Goldmound'), hydrangea (Hydrangea paniculata 'Grandiflora'), weigela (Weigela florida 'Alexandra'), ninebark (Physocarpus opulifolius 'Summer Wine'), and willow (Salix integra 'Hakura Nishiki')] were obtained from Canadale Nurseries Ltd. (St. Thomas, Ontario, Canada). They were grown in $1-\mathrm{L}$ pots containing, by volume, $55 \%$ composted pine bark, $25 \%$ sphagnum peatmoss, and $10 \%$ compost amended with 1 $\mathrm{kg} \cdot \mathrm{m}^{-3}$ surfactant (Soax; JBK, St. Catharines, Ontario, Canada), $1 \mathrm{~kg} \cdot \mathrm{m}^{-3}$ micronutrient mix (Micromax; Scotts Co., Marysville, $\mathrm{OH}), 8 \mathrm{~kg} \cdot \mathrm{m}^{-2}$ of a $15 \mathrm{~N}-3.9 \mathrm{P}-10 \mathrm{~K}$ resincoated, controlled-release fertilizer (Osmocote Plus $15-9-12,5$ to 6 months, $21{ }^{\circ} \mathrm{C}$; Scotts Co.), and $1 \mathrm{~kg} \cdot \mathrm{m}^{-3}$ of dolomitic limestone. Transplanted liners were pruned to uniform size and irrigated daily with University of Guelph untreated well water 3 weeks before the start of the experiment. The free chlorine concentration of the well water was measured before watering each day. The free chlorine concentration of the well water averaged $0.04 \pm 0.008 \mathrm{mg} \cdot \mathrm{L}^{-1}$.

The experiment was conducted at an outdoor nursery site at the University of Guelph, Ontario, Canada (lat. $43^{\circ} 34^{\prime}$ N) from 6 Sept. 2006 to 19 Oct. 2006. The day and night average air temperatures were 15 and $11^{\circ} \mathrm{C}$, respectively, and the average daily solar radiation was $11.2 \mathrm{MJ} \cdot \mathrm{m}^{-2}$. The experiment was a completely randomized design with five free chlorine concentration treatments and five plant species. Each free chlorine concentration treatment had three replicates and each replicate consisted of five plants of each species. All the measurements were conducted on three of the five plants in each replicate. Each plant was a subsample and the average of the three subsamples was treated as one replicate. Within each experimental unit there was one emitter irrigating the five plants placed at a distance of $0.15 \mathrm{~m}$ in a circle around the emitter and plants placed $0.10 \mathrm{~m}$ away from each other. Each emitter was directed to spray the irrigation treatment water above the plant canopy. The emitter application rate was $10.25 \mathrm{~mL} \cdot \mathrm{s}^{-1}$ with a coverage area of $6900 \mathrm{~cm}^{2}$. Plants were irrigated $1 \mathrm{~h}$ per day, which delivered 100
$\mathrm{mL} \cdot \mathrm{d}^{-1}$ of treatment irrigation water to each plant over the course of the 6-week experiment. The equivalent rates of free chlorine applied were: 0.04 (well water), 2.5, 5, 10, and $20 \mathrm{mg} \cdot \mathrm{L}^{-1}$. University of Guelph well water was used as the control. Chlorinated water for each treatment was freshly prepared before each irrigation by adding sodium hypochlorite stock solution to University of Guelph well water. The stock solution was prepared with $4 \%$ to $6 \%$ sodium hypochlorite (Fisher Scientific, Whitby, Ontario, Canada) and double-distilled water. The $\mathrm{pH}$ of each of the five free chlorine treatments was adjusted to 6.5 to 7.0 with hydrochloric acid as chlorine is reported to be the most effective at this $\mathrm{pH}$ range (Frink and Bugbee, 1987). Free chlorine concentrations were measured colorimetrically with a C201 Oakton Colorimeter (Oakton Instruments, Vermont Hills, IL) at the tank in which the chlorinated irrigation water was prepared and at the emitter. Free chlorine concentrations were measured using the protocol specific to the C201 Oakton Colorimeter (Oakton Instruments).

C201 Oakton Colorimeter. A 10-mL sample of chlorinated irrigation water was added to a clean and dry sample vial and placed into the sample well of the colorimeter to blank the instrument. One N,N-diethyl-p-phenylenediamine (DPD) free reagent packet was added to the sample and mixed for $20 \mathrm{~s}$ by inverting the vial repeatedly until the DPD free reagent was dissolved. The free residual chlorine in the sample was allowed to react with the DPD for $2 \mathrm{~min}$ and then the free residual chlorine concentration was read immediately by the colorimeter. The free residual chlorine reacts with the DPD creat- ing a pink color and the depth of the pink color produced is proportional to the free residual chlorine concentration. The amount of $525 \mathrm{~nm}$ light from a light-emitting diode absorbed by the pink color is measured through a silicon photodiode and is converted into the free residual chlorine concentration.

Samples and measurements. Phytotoxic response of plants was determined by observing visual injury and growth. Growth rates and aesthetic appearance are parameters that have a direct impact on the marketability of plants; therefore, they were used to determine the critical free chlorine threshold of nursery crops. The critical free chlorine threshold was defined in this study as the lowest free chlorine concentration at which there was visible leaf injury and/or a significant reduction in any of the measured growth parameters.

Visual injury (i.e., necrotic mottling, necrosis, chlorosis, premature abscission of foliage, leaf discoloration) of plant leaves was observed and recorded daily. Leaf chlorophyll content index (CCI) was measured with a chlorophyll meter (CCM-200; OptiSciences, Tyngboro, MA) and leaf chlorophyll fluorescence $\left(\mathrm{F}_{\mathrm{v}} / \mathrm{F}_{\mathrm{m}}\right)$ was measured with a Fluorescence Monitoring System (FMS; Hansatech Inst., Norfolk, UK) as described by Zheng et al. (2004) at the onset of visual injury and 1 week before final harvest. Leaf net $\mathrm{CO}_{2}$ exchange rate (NCER) and stomatal conductance $\left(g_{\mathrm{S}}\right)$ were measured using a portable infrared gas analyzer photosynthesis system (LI-COR 6400; LICOR, Lincoln, NE) 1 week before final harvest. All the NCER and $g_{\mathrm{S}}$ measurements were conducted under a photosynthetically active radiation of $300 \mu \mathrm{mol} \cdot \mathrm{m}^{-2} \cdot \mathrm{s}^{-1}$ with a

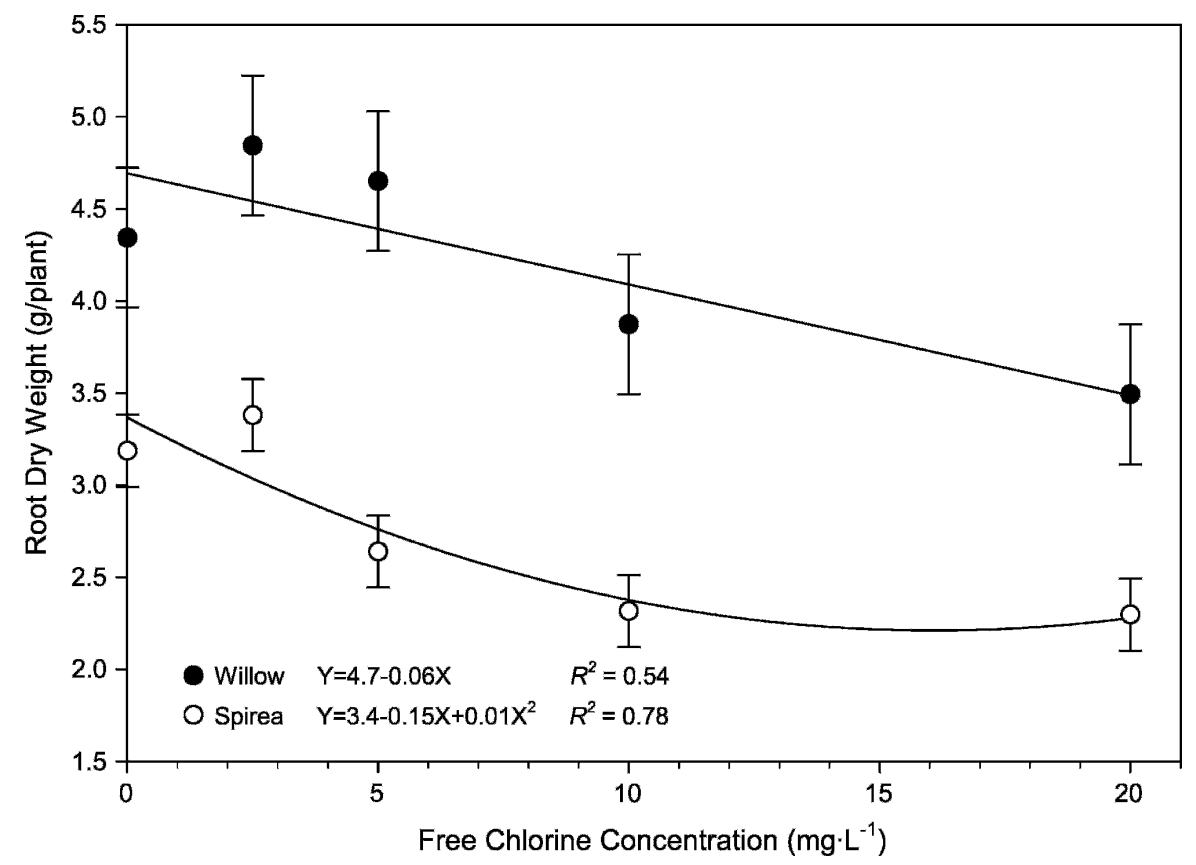

Fig. 1. Regression analysis of the effects of five free chlorine concentrations $\left(\mathrm{mg} \cdot \mathrm{L}^{-1}\right)$ on the root dry weight of willow (Salix integra 'Hakura Nishiki') and spirea (Spiraea japonica 'Goldmound'). A regression line was shown only when there was a significant treatment effect. The symbols $(\mathbf{O}$ and $\bigcirc)$ represent the means of three replicates and the error bars represent \pm the SE of the mean. 
reference $\mathrm{CO}_{2}$ concentration of 400 $\mu \mathrm{mol} \cdot \mathrm{m}^{-2} \cdot \mathrm{s}^{-1}$ and a block temperature of $24.0 \pm 0.07{ }^{\circ} \mathrm{C}$. CCI, $\mathrm{F}_{\mathrm{v}} / \mathrm{F}_{\mathrm{m}}, \mathrm{NCER}$, and $g_{\mathrm{S}}$ were measured on the youngest fully expanded leaf without visible injury of three subsamples per replicate.

Three randomly chosen plants from each replicate were harvested on 20 Oct. 2006 (day 46). Plants were cut at the substrate surface and shoot height was measured. Leaf area (LA) of each plant was measured using a leaf area meter (LI-3100; LI-COR). Plant parts were dried to a constant weight at $65^{\circ} \mathrm{C}$ and then weighed. Plant total dry weight was calculated as the sum of dry weights for all the plant parts. Shoot-to-root ratio $(\mathrm{S} / \mathrm{R})$ was calculated by dividing the sum of leaf and stem dry weights by root dry weight. Specific leaf area (SLA, $\mathrm{cm}^{2} \cdot \mathrm{g}^{-1}$ ) was calculated by dividing leaf area by leaf dry weight.

Statistical analysis. SAS software version 9.1 (SAS Institute; Cary, NC) was used to perform statistical analysis. Responses were analyzed by orthogonal partition and regression analyses using PROC GLM after testing for normality and homogeneity (Bowley, 1999). If the partitioning variance analysis indicated a significant $(P<0.05)$ treatment effect, then the treatment effects were partitioned into one or more regression effects followed by estimation of regression parameters for best-fit regression (linear, quadratic, or cubic). Each species was analyzed separately.

\section{Results}

All five species showed some foliar injury, growth differences, and/or physiological effects as a result of chlorine phytotoxicity, although there were marked differences among species.

Visual injury. Spirea leaves started to show marginal necrotic mottling as a purplish black color after $17 \mathrm{~d}$ of treatment with 20 $\mathrm{mg} \cdot \mathrm{L}^{-1}$ of free chlorine. On day 22 , necrotic mottling developed on plants treated with 10 $\mathrm{mg} \cdot \mathrm{L}^{-1}$ of free chlorine. No visible leaf injury was observed on spirea plants treated with 5 $\mathrm{mg} \cdot \mathrm{L}^{-1}$ or less of free chlorine. On day 28 , spirea began to exhibit premature leaf abscission in all treatments. Premature leaf abscission continued to gradually increase in severity in spirea plants irrigated with 5 $\mathrm{mg} \cdot \mathrm{L}^{-1}$ or more of free chlorine; however, this phenomenon was not observed on plants treated with $2.5 \mathrm{mg} \cdot \mathrm{L}^{-1}$ or less of free chlorine. Hydrangea and weigela also had premature abscission of foliage in all treatments after day 28, but these two species did not exhibit necrotic mottling as observed with spirea. Leaf abscission continued to increase in severity for hydrangea and weigela irrigated with $5 \mathrm{mg} \cdot \mathrm{L}^{-1}$ or more of free chlorine, but not on plants irrigated with 2.5 $\mathrm{mg} \cdot \mathrm{L}^{-1}$ or less of free chlorine.

Ninebark foliage treated with $20 \mathrm{mg} \cdot \mathrm{L}^{-1}$ of free chlorine started to show leaf discoloration on day 17 . The olive green discoloration was in contrast to the dark red pigmentation of leaves in the control treat-

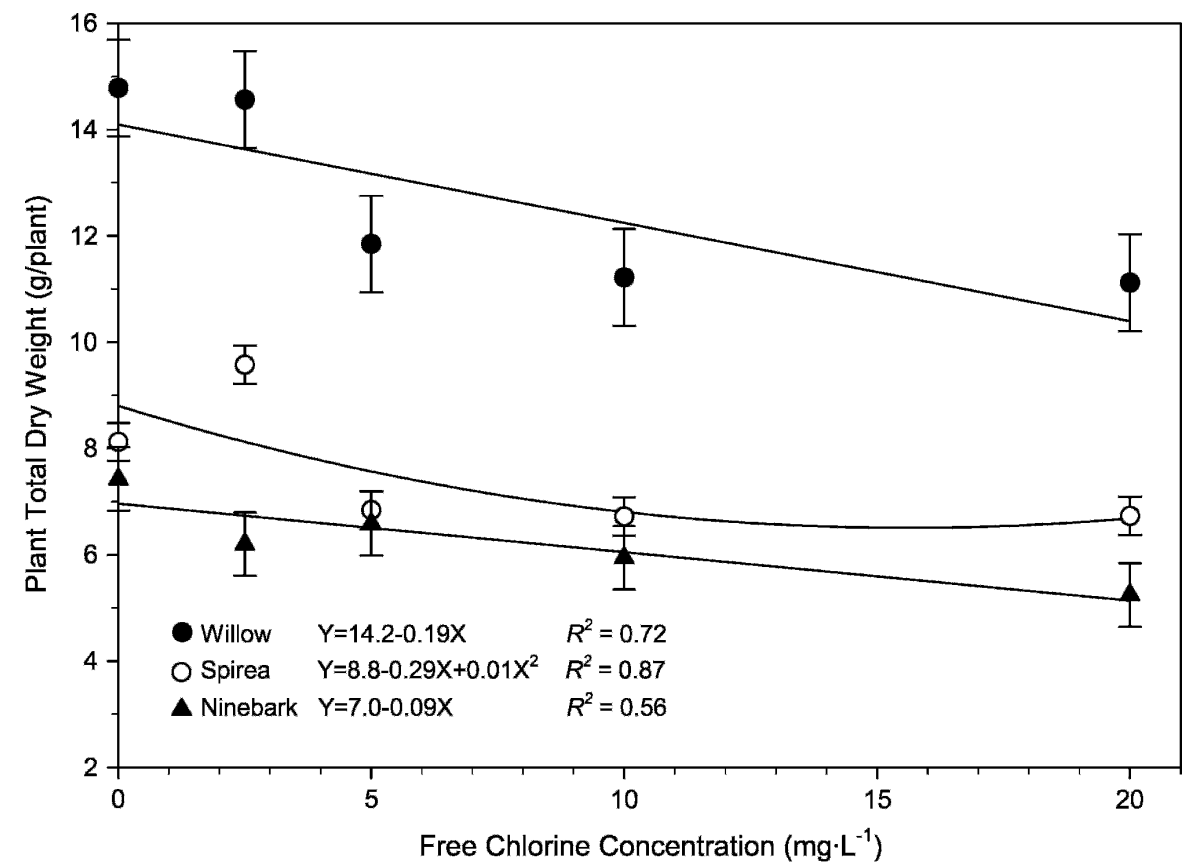

Fig. 2. Regression analysis of the effects of five free chlorine concentrations $\left(\mathrm{mg} \cdot \mathrm{L}^{-1}\right)$ on the plant total dry weight of willow (Salix integra 'Hakura Nishiki'), spirea (Spiraea japonica 'Goldmound'), and ninebark (Physocarpus opulifolius 'Summer Wine'). A regression line was shown only when there was a significant treatment effect. The symbols $(\boldsymbol{O}, \bigcirc$, and $\mathbf{\Delta})$ represent the means of three replicates and the error bars represent \pm the SE of the mean.

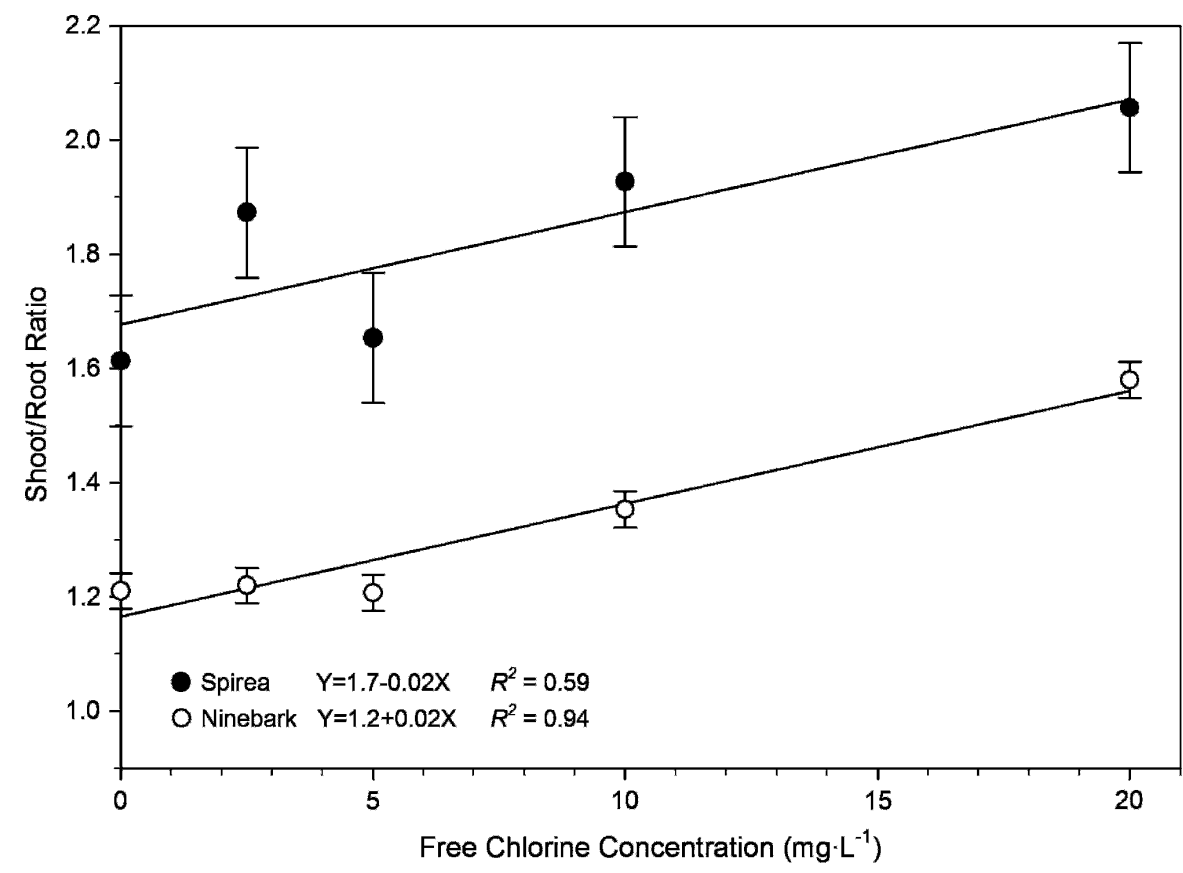

Fig. 3. Regression analysis of the effects of five free chlorine concentrations $\left(\mathrm{mg} \cdot \mathrm{L}^{-1}\right)$ on the shoot-to-root ratio of spirea (Spiraea japonica 'Goldmound') and ninebark (Physocarpus opulifolius 'Summer Wine'). A regression line was shown only when there was a significant treatment effect. The symbols

$($ and $O$ ) represent the means of three replicates and the error bars represent \pm the SE of the mean.

ment. Discoloration continued to cover the leaf surface and by day 45 , ninebark plants irrigated with $5 \mathrm{mg} \cdot \mathrm{L}^{-1}$ or more of free chlorine exhibited green discoloration. On day 38, marginal chlorosis as a light pink bleaching effect appeared on ninebark treated with $5 \mathrm{mg} \cdot \mathrm{L}^{-1}$ or more of free chlorine. No discoloration or chlorosis was observed on ninebark plants treated with $2.5 \mathrm{mg} \cdot \mathrm{L}^{-1}$ or less of free chlorine.

Willow leaves showed marginal necrosis as an orange-brown burning after $28 \mathrm{~d}$ of treatment at $10 \mathrm{mg} \cdot \mathrm{L}^{-1}$ or more of free chlorine, which then appeared on plants 
treated with $5 \mathrm{mg} \cdot \mathrm{L}^{-1}$ of free chlorine on day 38. No necrosis was observed on willow plants treated with $2.5 \mathrm{mg} \cdot \mathrm{L}^{-1}$ or less of free chlorine.

Growth. Plant growth of different plant species differed in their response to chlorine. According to the regression analyses, root and total plant dry weight and $\mathrm{S} / \mathrm{R}$ of spirea were significantly affected by free chlorine at 5 , 5, and $2.5 \mathrm{mg} \cdot \mathrm{L}^{-1}$, respectively (Figs. $1-3$ ). No significant treatment effect was observed for height, shoot dry weight, LA, and SLA of spirea (data not shown). For hydrangea, only LA was significantly affected by free chlorine at $5 \mathrm{mg} \cdot \mathrm{L}^{-1}$ (Fig. 4). No significant treatment effect was observed for the height, shoot dry weight, root dry weight, plant total dry weight, S/R, and SLA of hydrangea (data not shown). Weigela LA and SLA displayed significant treatment effects at 2.5 and 20 $\mathrm{mg} \cdot \mathrm{L}^{-1}$, respectively (Figs. 4 and 5). No significant treatment effect was observed for the height, shoot dry weight, root dry weight, plant total dry weight, and $S / R$ of weigela (data not shown). Ninebark plant total dry weight and $\mathrm{S} / \mathrm{R}$ displayed significant treatment effects at $10 \mathrm{mg} \cdot \mathrm{L}^{-1}$ (Figs. 2 and 3). No significant treatment effect was observed for the height, shoot dry weight, root dry weight, LA, and SLA of ninebark (data not shown). Root dry weight, plant total dry weight, LA, and shoot dry weight of willow were significantly affected by free chlorine at $20,5,2.5$, and $5 \mathrm{mg} \cdot \mathrm{L}^{-1}$, respectively (Figs. 1 , 2,4 , and 6). No significant treatment effect was observed for the height, S/R, and SLA of willow (data not shown).

Physiological responses. No significant treatment effects were observed for leaf CCI, $F_{v} / F_{m}$, and NCER (data not shown). Leaf $g_{\mathrm{S}}$ of spirea and hydrangea decreased, and willow and ninebark increased as free chlorine concentrations in irrigation water increased (Fig. 7). Chlorine treatments did not affect these physiological responses for weigela.

\section{Discussion}

To prevent the spread of plant pathogen propagules through recycled irrigation water, some nursery and greenhouse industries chlorinate their irrigation water and system; however, the use of chlorinated irrigation water may lead to severe phytotoxic effects and reduce the marketability of the plants. All plant species in this study showed one or more signs of visual injury resulting from chlorine toxicity, including necrotic mottling, necrosis and chlorosis of foliage, decreased plant height, and increased premature abscission of foliage with species differing in their sensitivity to treatment-free chlorine concentrations in the irrigation water. Treatment responses in growth and physiological parameters also differed among the species ranging from several parameters such as shoot, root, and plant total dry weight and LA being sensitive for willow to only LA being sensitive for hydrangea. Therefore, visible injury and responses

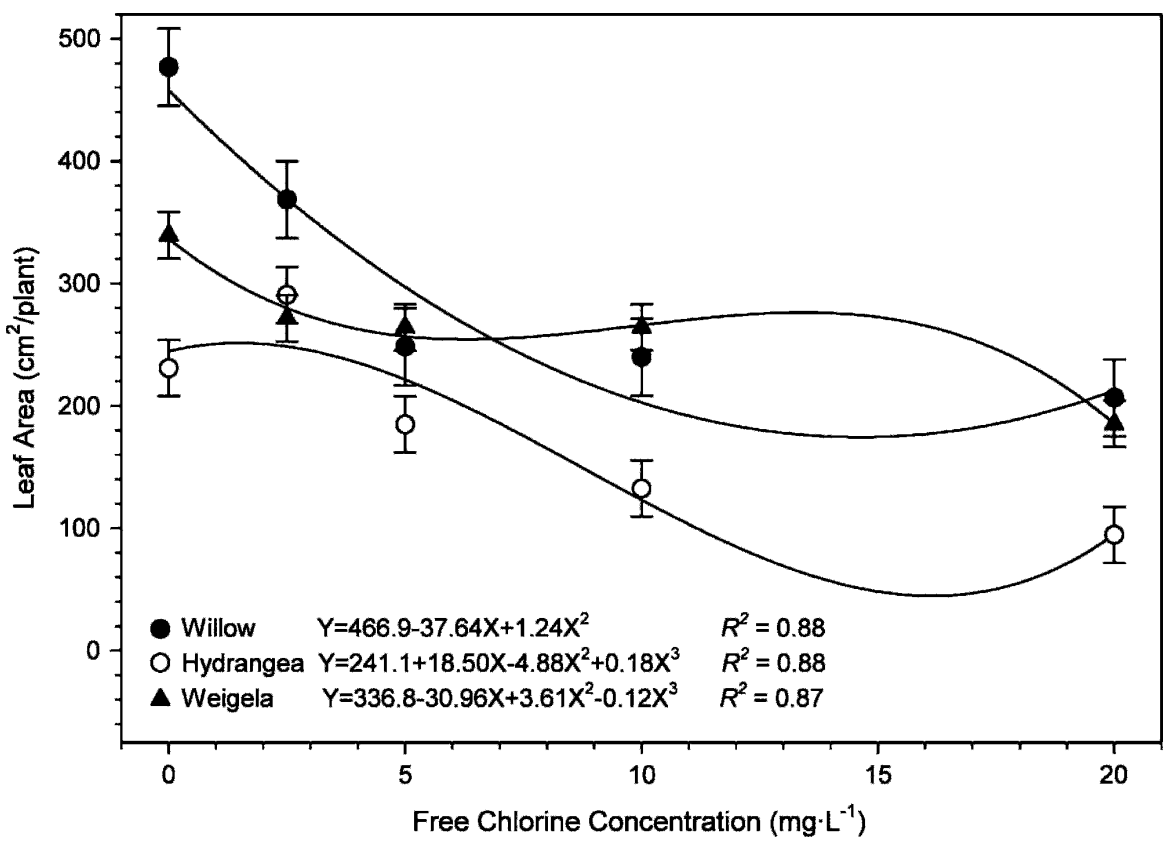

Fig. 4. Regression analysis of the effects of five free chlorine concentrations $\left(\mathrm{mg} \cdot \mathrm{L}^{-1}\right)$ on the leaf area of willow (Salix integra 'Hakura Nishiki'), hydrangea (Hydrangea paniculata 'Grandiflora'), and weigela (Weigela florida 'Alexandra'). A regression line was shown only when there was a significant treatment effect. The symbols $(\boldsymbol{\bullet}, \bigcirc$, and $\mathbf{\Delta})$ represent the means of three replicates and the error bars represent \pm the SE of the mean.

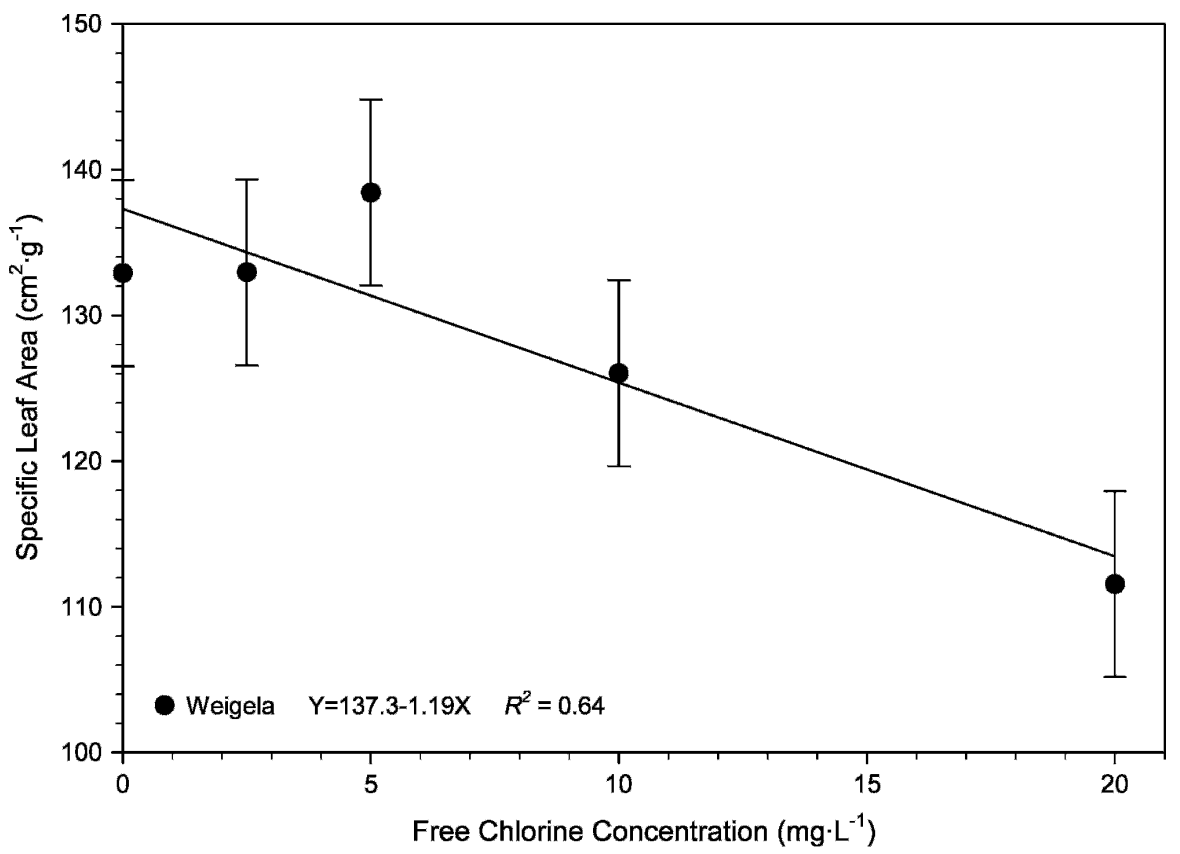

Fig. 5. Regression analysis of the effects of five free chlorine concentrations $\left(\mathrm{mg} \cdot \mathrm{L}^{-1}\right)$ on the specific leaf area of weigela (Weigela florida 'Alexandra'). A regression line was shown only when there was a significant treatment effect. The symbol $(\bigcirc)$ represents the means of three replicates and the error bars represent \pm the SE of the mean.

in growth and physiological parameters differed depending on the plant species and their sensitivity to free chlorine.

Schreuder and Brewer (2001a) reported that necrotic mottling was characterized by red and black dark spots on the leaf surface, which is in agreement with the necrotic mottling seen in spirea. The premature abscission of foliage in spirea, hydrangea, and weigela has also been reported in kalanchoe treated with sodium hypochlorite (Frink and Bugbee, 1987). Leaf chlorosis, seen in ninebark, has also been reported in Pinus ponderosa exposed to chlorine gas pollution (Schreuder and Brewer, 2001a) and radish and lettuce treated with chlorine dioxide (Carrillo et al., 1996). Needles of Pinus ponderosa exposed to chlorine gas pollution 


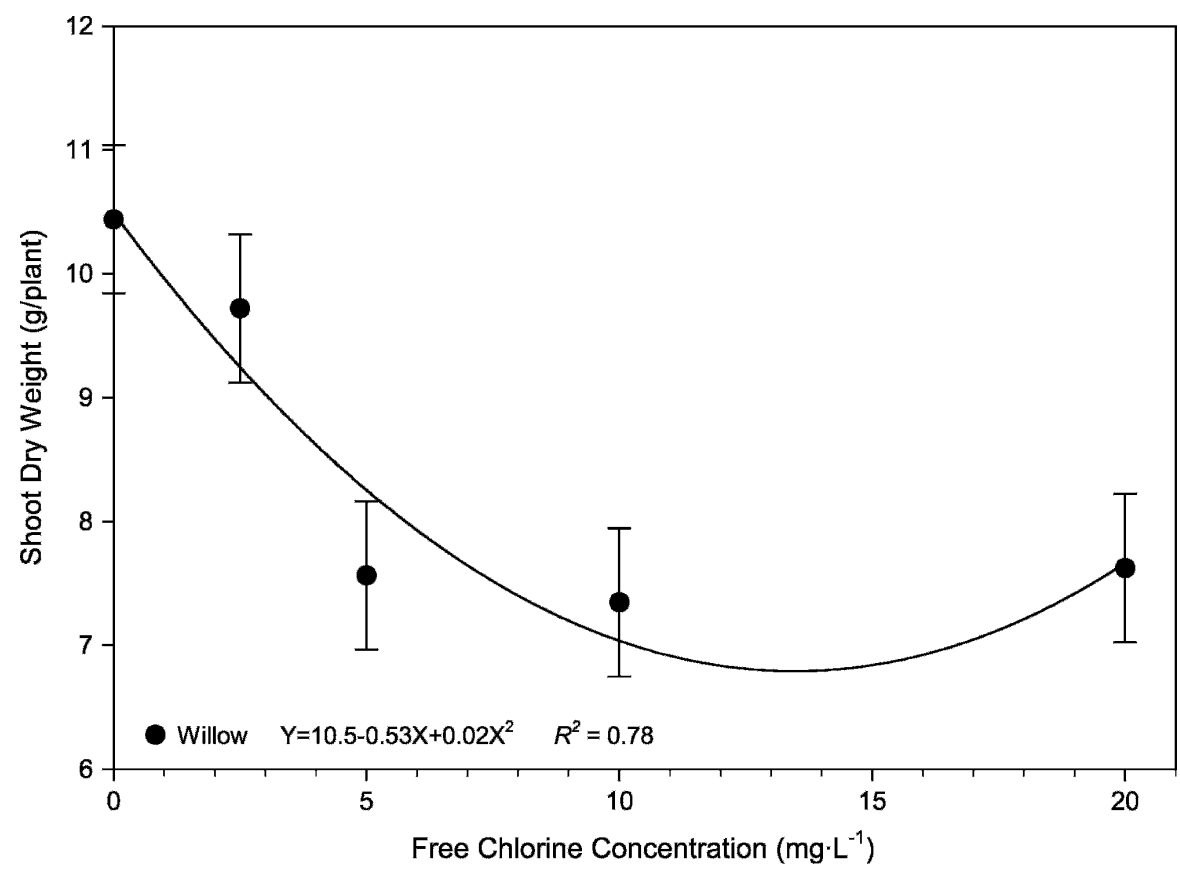

Fig. 6. Regression analysis of the effects of five free chlorine concentrations $\left(\mathrm{mg} \cdot \mathrm{L}^{-1}\right)$ on the shoot dry weight of willow (Salix integra 'Hakura Nishiki'). A regression line was shown only when there was a significant treatment effect. The symbol $(\bigcirc)$ represents the means of three replicates and the error bars represent \pm the SE of the mean.

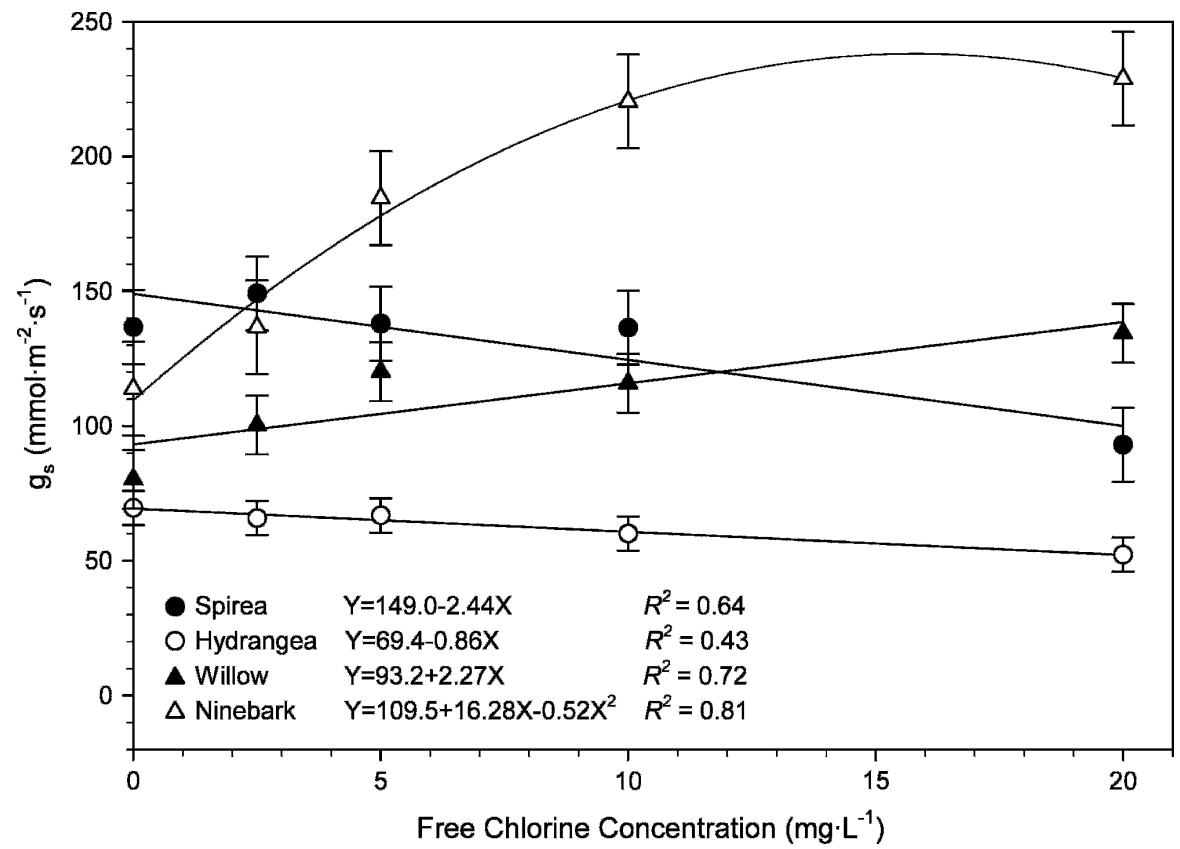

Fig. 7. Regression analysis of the effects of five free chlorine concentrations $\left(\mathrm{mg} \cdot \mathrm{L}^{-1}\right)$ on the stomata conductance of spirea (Spiraea japonica 'Goldmound'), hydrangea (Hydrangea paniculata 'Grandiflora'), willow (Salix integra 'Hakura Nishiki'), and ninebark (Physocarpus opulifolius 'Summer Wine'). A regression line was shown only when there was a significant treatment effect. The symbols $(\boldsymbol{\bullet}, \mathrm{O}, \boldsymbol{\Lambda}$, and $\Delta$ ) represent the means of three replicates and the error bars represent \pm the $\mathrm{SE}$ of the mean.

had the same orange-brown necrosis as seen in willow (Schreuder and Brewer, 2001a). The decrease in growth in willow has also been reported in radish and lettuce treated with chlorine dioxide (Carrillo et al., 1996), tobacco (Karaivazoglou et al., 2005), and marigold and impatiens (Brown, 1991) irri- gated with water containing chlorine. An increase in the shoot-to-root ratio indicates that plant roots are more sensitive than shoots (Zheng et al., 2004), so an increase in $S / R$ in this experiment indicates that the root is more sensitive to chlorine than the shoot for spirea and ninebark. This is consistent with lack of treatment effects on spirea and ninebark's shoot dry weight. Significant treatment effects for LA of hydrangea and LA and SLA of weigela were consistent with their premature foliar abscission. Vijayan and Bedi (1989) also found a decrease in leaf area in mango (Mangifera indica L.), rayan (Manilkara hexandra Dubard), and jamun (Syzygium cumini Skeels) exposed to chlorine gas pollution. Other researchers have also reported excessive chlorine reducing leaf growth in other plant species (Karaivazoglou et al., 2005). Oesterheld (1992) indicated that plant growth rate depended on plant biomass and the removal of biomass resulted in a reduction in plant growth rate. This is consistent with the decrease in willow's shoot dry weight, root dry weight, total dry weight, and LA. Acid rain and acid mist had the same effects on plants as $\mathrm{Cl}_{2}$ because they form a highly acidic solution in an aqueous phase consisting of hydrochloric acid $(\mathrm{HCl})$ and $\mathrm{HOCl}$ (Schreuder and Brewer, 2001a). Acid rain and acid mist affect the composition and structure of plant cuticles and their production of waxes (Schreuder and Brewer, 2001b). This leads to cuticular damage causing increased rates of cuticular transpiration, which may have manifested as increased $g_{\mathrm{S}}$ as measured by the leaf gas exchange measuring system. This may explain the increase of $g_{\mathrm{S}}$ by some plants to free chlorine because free chlorine consists of $\mathrm{HOCl}$ and $\mathrm{Cl}_{2}$. In our research, increased $g_{\mathrm{S}}$ was recorded for ninebark and willow; however, spirea and hydrangea displayed a decrease in $g_{\mathrm{S}}$. The decrease of $g_{\mathrm{S}}$ for spirea and hydrangea is unexplained.

If we define the critical free chlorine threshold as the lowest free chlorine concentration at which there was visible leaf injury and/or a significant reduction in any of the measured growth parameters, based on our results, the critical free chlorine thresholds of spirea, hydrangea, weigela, and willow was $2.5 \mathrm{mg} \cdot \mathrm{L}^{-1}$ and for ninebark $5 \mathrm{mg} \cdot \mathrm{L}^{-1}$.

Although this experiment was conducted in the fall with cool temperatures, the plants were still actively growing. Net increases of plant shoot dry weight ranged from 26\% (hydrangea) to $105 \%$ (willow). Earlier in the growing season when plant tissues are softer and more irrigation is needed as a result of higher evaporative demand, it is possible that free chlorine thresholds for nursery liners may be lower.

Frink and Bugbee (1987) stated that a chlorine concentration less than $1 \mathrm{mg} \cdot \mathrm{L}^{-1}$ should not adversely affect the growth or appearance of plants, and Brown (1991) showed that a chlorine concentration of less than $5 \mathrm{mg} \cdot \mathrm{L}^{-1}$ did not have any significant effects on marigold and impatiens. Based on our results, we suggest that a chlorine concentration less than $2.5 \mathrm{mg} \cdot \mathrm{L}^{-1}$ should not adversely affect the growth or appearance of plants. Differences in results can be attributed to different plant species used in all experiments. Frink and Bugbee (1987) and Brown (1991) used herbaceous ornamental and vegetable greenhouse crops, whereas we used 
woody ornamental shrubs. Differences in results can also be explained by differences in the frequency of exposure to free chlorine treatments. Our plants were exposed to free chlorine on a daily basis, which followed a typical nursery irrigation schedule, whereas Frink and Bugbee (1987) only watered once or twice a week. The morphological and anatomical structure of plants and plant parts may also contribute to the differences in chlorine sensitivity between species used in all three experiments. Some plants have hairy leaves, which may allow chlorinated water to be retained on the leaf surface allowing for longer exposure, whereas other plants have waxy leaves, which may repel water, thereby decreasing exposure. The plant species in our experiment have varying degrees in the amount of wax, softness, and hair on the leaves, which may have contributed to each plant's chlorine sensitivity; however, there is no direct correlation between the morphological differences of the plants and their chlorine sensitivity.

Plant species differ in their sensitivity to chlorine concentrations in irrigation water, which can influence plant quality, growth, and physiological performance in nurseries using chlorinated irrigation water. The results of this study indicated that using a free chlorine concentration less than $2.5 \mathrm{mg} \cdot \mathrm{L}^{-1}$, applied daily through overhead irrigation, should not adversely affect the growth or appearance of woody shrubbery nursery liners. Because our research was conducted in the fall, additional research is needed to determine whether chlorine sensitivity of liners is the same for a spring planting when warmer growing conditions are likely to occur.

\section{Literature Cited}

Bowley, S. 1999. A hitchhiker's guide to statistics in plant biology. Any Old Subject Books. Guelph, Ontario, Canada.

Brown, D. 1991. Effect of irrigating flowering plants and turf grass with chlorinated water. Ontario Hydro Research Division Report K. 91-73, Ontario, Canada.

Carrillo, A., M.E. Puente, and Y. Bashan. 1996. Application of diluted chlorine dioxide to radish and lettuce nurseries insignificantly reduced plant development. Ecotoxicol. Environ. Saf. 35:57-66.

Ehret, D.L., B. Alsanius, W. Wohanka, J.G. Menzies, and R. Utkhede. 2001. Disinfestation of recirculating nutrient solutions in greenhouse horticulture. Agronomie 21:323-339.

Frink, C.R. and G.J. Bugbee. 1987. Response of potted plants and vegetable seedlings to chlorinated water. HortScience 22:581-583.

Fueda, W. and E. Hirasawa. 1994. Chloride absorption and distribution in chlorine-deficient Pharbitis nil. Plant Soil 164:261-266.

Havard, P. 2003. Farm irrigation water safety initiative final report Apr. 2003. Horticulture Nova Scotia, Nova Scotia Agricultural College, Nova Scotia, Canada.

Hong, C.X., P.A. Richardson, P. Kong, and E.A. Bush. 2003. Efficacy of chlorine on multiple species of Phytophthora in recycled nursery irrigation water. Plant Dis. 87:1183-1189.

Igura, N., M. Fujii, M. Shimoda, and I. Hayakawa. 2004. Research note: Inactivation efficiency of ozonated water for Fusarium oxysporum conidia under hydroponic greenhouse conditions. Ozone: Sci. and Eng. 26:517-521.

Karaivazoglou, N.A., D.K. Papakosta, and S. Divanidis. 2005. Effect of chloride in irrigation water and form of nitrogen fertilizer on Virginia (flue-cured) tobacco. Field Crops Res. 92:61-74.

Kuhajek, J.M., S.N. Jeffers, M. Slattery, and D.E. Wedge. 2003. A rapid microbioassay for dis- covery of novel fungicides for Phytophthora spp. Phytopathology 93:46-53.

Newman, S.E. 2004. Disinfecting irrigation water for disease management. 20th Annu. Conf. on Pest Mgt. on Ornamentals. San Jose, CA, 20 22 Feb. 2004.

Oesterheld, M. 1992. Effect of defoliation intensity on aboveground and belowground relative growth rates. Oecologia 92:313-316.

Ridgway, H.F. and B.H. Olson. 1982. Chlorine resistance patterns of bacteria from two drinking water distribution systems. Appl. Environ. Microbiol. 44:972-987.

Schoene, G., T. Yeager, and D. Haman. 2006. Survey of container nursery irrigation practices in west-central Florida: An educational opportunity. HortTechnology 16:682-685.

Schreuder, M.D.J. and C.A. Brewer. 2001a. Effects of short-term, high exposure to chlorine gas on morphology and physiology of Pinus ponderosa and Pseudotsuga menziesii. Ann. Bot. (Lond.) 88:187-195.

Schreuder, M.D.J. and C.A. Brewer. 2001b. Persistent effects of short-term, high exposure to chlorine gas on physiology and growth of Pinus ponderosa and Pseudotsuga menziesii. Ann. Bot. (Lond.) 88:197-206.

Skimina, C.A. 1992. Recycling water, nutrients, and waste in the nursery industry. HortScience 27:968-971.

Tietjen, L., D. Bossemeyer, and N. McIntosh. 2003. Infection prevention guidelines for healthcare facilities with limited resources. JHPIEGO Corporation, Baltimore, MD.

Vijayan, R. and S.J. Bedi. 1989. Effect of chlorine pollution on three fruit tree species at Ranoli near Baroda, India. Environ. Pollut. 57:97-102.

White, G.C. 1992. The handbook of chlorination and alternative disinfectants. 3rd Ed. Van Nostrand Reinhold, New York, NY.

Zheng, Y., L. Wang, and M.A. Dixon. 2004. Response to copper toxicity for three ornamental crops in solution culture. HortScience 39: 1116-1120. 